\title{
Intentional overdose of liraglutide in a non-diabetic patient causing severe hypoglycemia
}

\author{
Kevin J. Solverson, MD, MSc*; Holly Lee, $\mathrm{MD}^{\dagger}$; Christopher J. Doig, MD, MSc ${ }^{\ddagger}$
}

\section{ABSTRACT}

Cases of liraglutide overdose are rare in the literature. Prior reports have not found hypoglycemia related to the medication overdose. We describe a case of a non-diabetic patient who intentionally overdosed on liraglutide leading to severe hypoglycemia. The patient required admission to the intensive care unit for a dextrose infusion and close monitoring. Glucagon-like protein-1 agonists are recognized for their safety and rarely causing hypoglycemia in diabetic patients. However, in this case the patient's non-diabetic status may have put him at risk for hypoglycemia in contrast to prior cases showing no hypoglycemia in diabetic patients. The case highlights the possible dangers of liraglutide overdose and need for blood glucose monitoring in the acute presentation.

\section{RÉSUMÉ}

Il existe très peu de cas de surdosage intentionnel par le liraglutide dans la documentation médicale, et les rapports antérieurs ne font état d'aucun cas d'hypoglycémie lié à un surdosage par le liraglutide. Sera exposé dans l'article un cas de surdosage intentionnel par le liraglutide chez un patient non diabétique, ce qui a entrainé une hypoglycémie grave. Son état a nécessité l'admission au service de soins intensifs pour des perfusions de dextrose et une surveillance étroite. Les agonistes des récepteurs du peptide-1 apparenté au glucagon sont connus pour leur innocuité et ils causent rarement de l'hypoglycémie chez les diabétiques. Toutefois, dans le cas présent, le fait d'être non diabétique comportait, pour le patient, un risque d'hypoglycémie, contrairement aux cas antérieurs d'absence d'hypoglycémie chez les diabétiques. Aussi l'exposé fait-il ressortir les risques du surdosage par le liraglutide et la nécessité de la surveillance de la glycémie dans les cas aigus.

Keywords: liraglutide, glucagon-like peptide 1, drug overdose

\section{CASE REPORT}

A 46-year-old male developed sudden onset confusion and agitation at home and was unable to answer questions from his partner. Emergency medical services (EMS) were called, and on arrival, the patient's Glasgow Coma Scale was reported as $8 / 15$; his vital signs were: blood pressure of 124/76, heart rate of 104 beats per minute, temperature of $36.0^{\circ} \mathrm{C}$, and respiratory rate of 18 breaths/minute. Blood glucose testing revealed a level of $1.3 \mathrm{mmol} / \mathrm{L}$ (normal range $3.3-11.0 \mathrm{mmol} / \mathrm{L}$ ). Immediate administration of $50 \mathrm{mmol}$ of intravenous (IV) dextrose quickly improved the patient's level of consciousness and blood glucose levels to $7 \mathrm{mmol} / \mathrm{L}$.

In the emergency department (ED), the patient admitted to attempting suicide by injecting $36 \mathrm{mg}$ of liraglutide subcutaneously (20 times the maximum recommended dose) that had been prescribed to his partner. He took the medication approximately five hours before becoming symptomatic. The patient thought he might have taken some of his partner's other medications; however, all her medications were in their respective blister packs. The patient's vital signs and mental status were stable, and he was initiated on an IV dextrose infusion (Figure 1). Approximately five hours after the dextrose infusion was started, the patient had a second hypoglycemic episode $(2.8 \mathrm{mmol} / \mathrm{L})$ that corrected with a $50 \mathrm{~mL}$ bolus of $50 \% \mathrm{IV}$ dextrose. He initially required an infusion of $50 \%$ dextrose titrated up to $175 \mathrm{~mL} / \mathrm{h}$ to maintain a blood glucose level of $7.0 \mathrm{mmol} / \mathrm{L}$. The patient's serum levels of acetaminophen, salicylate, and ethanol were all negative. A comprehensive drug screen was not sent. Initial liver enzyme testing was normal: alanine aminotransferase, $36 \mathrm{U} / \mathrm{L}$; alkaline phosphatase, $63 \mathrm{U} / \mathrm{L}$; bilirubin total, $14 \mu \mathrm{mol} / \mathrm{L}$; lipase $38 \mathrm{U} / \mathrm{L}$; and lactate dehydrogenase $66 \mathrm{U} / \mathrm{L}$. The patient had an anion gap of 12, osmolar gap of 1 , and venous $\mathrm{pH}$ of 7.42. An electrocardiogram showed a normal sinus rhythm with a QTc of $457 \mathrm{~ms}$, and a chest x-ray was normal.

The patient had a history of borderline personality disorder, prior suicide attempts, and chronic pain.

From the *Department of Critical Care Medicine; †Department of Medicine, and; $¥$ Department of Community Health Sciences, Cumming School of Medicine, University of Calgary, Calgary, $A B$

Correspondence to: Dr. Christopher J. Doig, Department of Critical Care Medicine, Cumming School of Medicine, University of Calgary, 3134 Hospital Drive NW, Calgary, AB T2N 5A1, Canada; Email: cdoig@ucalgary.ca 


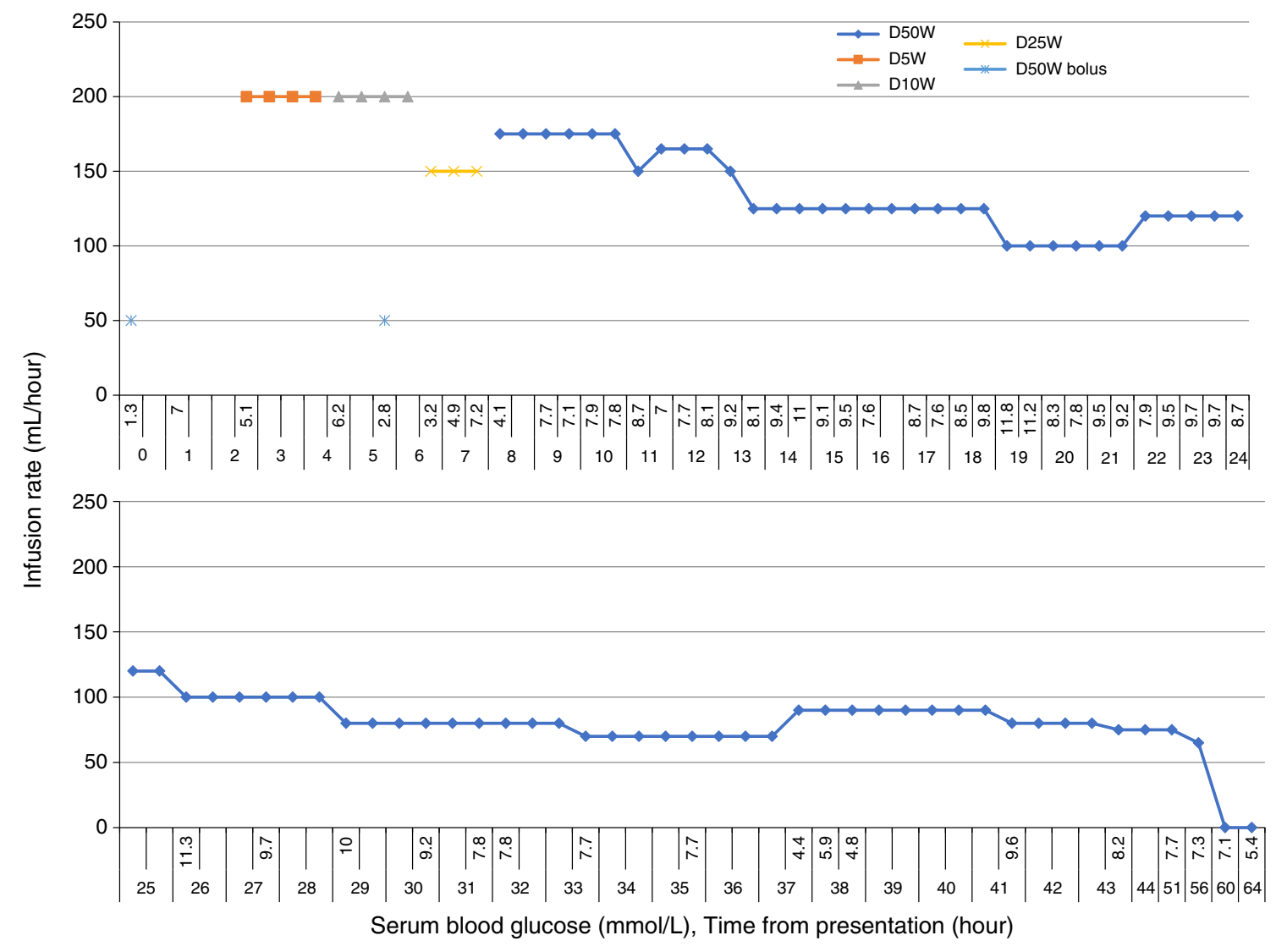

Figure 1. Glucose infusions to maintain serum blood glucose.

He had no history of diabetes (hemoglobin A1c of $5.4 \%$, one year prior). His home medications included gabapentin, acetaminophen, quetiapine, and zopiclone. His partner reported that the patient was out of his medications for several days and that there were no other medications available to him besides the liraglutide and the accounted for blister-packed medications. There were no other evident causes of hypoglycemia besides the liraglutide overdose, including liver disease, access to exogenous insulin, or alcohol toxicity.

The regional poison centre was consulted and recommended the administration of octreotide, in addition to IV dextrose and supportive care, hypothesizing that it may decrease the secretion of insulin as it does in sulfonylurea toxicity. Fifty micrograms of octreotide was administrated subcutaneously two hours after presentation and continued every six hours for three additional doses. It is unclear if there was any impact on the patient's blood glucose level. No glucagon was given.

The patient was admitted to the intensive care unit (ICU) where he was treated with an infusion of $50 \%$ dextrose that was weaned over 48 hours. There was no recurrent hypoglycemia for the 24 hours after discontinuation. At admission, the patient had persistent nausea, eight episodes of vomiting over 24 hours, and mild abdominal pain. He was treated with metoclopramide, $10 \mathrm{mg}$ IV every 8 hours, and acetaminophen, $500 \mathrm{mg}$ every 6 hours. The symptoms resolved after 24 hours. His liver functioning tests including lipase remained normal. The patient also required correction of hypophosphatemia and hypokalemia during the first 48 hours of the hospital admission. He did not experience any other adverse symptoms, made a full recovery, and was discharged home four days after admission.

\section{DISCUSSION}

This is the first reported case report of a liraglutide overdose causing severe hypoglycemia. There are only five reported cases in the literature of liraglutide overdose, four of which were in diabetic patients ${ }^{1-4}$ and one non-diabetic patient. ${ }^{5}$ In all the reported overdose cases, patients did not experience hypoglycemia, 
including a diabetic patient that took a single $72 \mathrm{mg}$ dose of liraglutide. ${ }^{1}$ Nausea, vomiting, and abdominal pain were the only symptoms in all reported cases and resolved over several days.

Liraglutide is a glucagon-like peptide-1 agonist (GLP-1) that was approved for the treatment of type II diabetes in Canada in 2015. The medication is administered once daily subcutaneously and has a half-life of 8-12 hours. ${ }^{6}$ GLP-1 is an incretin hormone, is secreted in response to caloric intake, potentiates glucosedependent insulin secretion from pancreatic beta-islet cells, inhibits glucagon secretion, delays gastric emptying, and exerts some other endocrine effects. Liraglutide is known to decrease the hemoglobin A1c by approximately $1.5 \% .^{7}$ Unlike other diabetic medications, hypoglycemia is rare if administering a GLP-1 agonist in isolation. ${ }^{7,8}$

In the absence of access to other oral hypoglycemic agents and insulin, it is possible this non-diabetic patient developed severe hypoglycemia from liraglutide in contrast to prior reports showing no hypoglycemia in diabetics. Diabetic patients have been shown to have a decreased expression of GLP-1 receptors and, therefore, a reduced dose response to GLP-1 agonists. ${ }^{9}$ In theory, a toxic dose of a GLP-1 agonist administered to a diabetic patient may not lead to a sufficient increase in endogenous insulin secretion to cause hypoglycemia. Additionally, diabetic patients have a relative insulin deficiency because of beta-islet cell dysfunction in combination with peripheral insulin resistance that may reduce the effect that a GLP-1 agonist has on blood glucose levels relative to a non-diabetic patient. A case report of a liraglutide overdose in a non-diabetic patient has been reported with no observed hypoglycemia; however, the patient had pancreatic insufficiency and was empirically treated with a single dose of glucagon on admission. ${ }^{5}$

There are currently no published guidelines on the treatment of a liraglutide overdose. Supportive care and consultation with a regional poison centre are recommended in the product monograph. ${ }^{10}$ It is unclear if octreotide or glucagon is effective for the treatment or prevention of hypoglycemia after a liraglutide overdose. Glucagon is a hormone that elevates serum glucose levels through gluconeogenesis and glycogenolysis and is the primary counterregulatory hormone to insulin. Through these mechanisms, glucagon administration may theoretically prevent recurrent hypoglycemia in GLP-1 agonist overdoses, although this has not been conclusively demonstrated. In this case of liraglutideinduced hypoglycemia, supportive care with an intravenous dextrose infusion and octreotide resulted in a full recovery and no other complications. Physicians and health care professionals should be vigilant in monitoring patients with a GLP-1 agonist overdose as hypoglycemia is possible that can require intensive glucose supplementation.

Competing interests: None declared.

\section{REFERENCES}

1. Nakanishi R, Hirose T, Tamura Y, Fujitani Y, Watada H. Attempted suicide with liraglutide overdose did not induce hypoglycemia. Diabetes Res Clin Pract 2013;99(1):e3-4.

2. Bode SF, Egg M, Wallesch C, Hermanns-Clausen M. 10-fold liraglutide overdose over 7 months resulted only in minor side-effects. 7 Clin Pharmacol 2013;53(7):785-6.

3. Elmehdawi RR, Elbarsha AM. An accidental liraglutide overdose: case report. Libyan 7 Med 2014;9(1):23055.

4. Madsen LR, Christiansen JJ. [A 45-fold liraglutide overdose did not cause hypoglycaemia]. Ugeskr Laeger 2015;177(5): V11140595.

5. Bowler M, Nethercott DR. Two lessons from the empiric management of a combined overdose of liraglutide and amitriptyline. A A Case Rep 2014;2(3):28-30.

6. Truven Health Analytics. DynaMed Plus Record No. 901231, Liraglutide, [updated 2016 Jan 20]. Ipswich, MA: EBSCO Information Services; 1995. Available at: http:// www.dynamed.com/login.aspx? direct $=$ true $\&$ site $=$ DynaMed \&id=901231.

7. Scott LJ. Liraglutide: a review of its use in adult patients with type 2 diabetes mellitus. Drugs 2014;74(18):2161-74.

8. Klein-Schwartz W, Stassinos GL, Isbister GK. Treatment of sulfonylurea and insulin overdose. Br $\mathrm{F}$ Clin Pharmacol 2016;81(3):496-504.

9. Cho YM, Fujita Y, Kieffer TJ. Glucagon-like peptide-1: glucose homeostasis and beyond. Annu Rev Physiol 2014; 76(1):535-59.

10. Victoza (liraglutide) [product monograph]. Mississauga, ON: Novo Nordisk Canada Inc; 2017. Available at: http:// www.novonordisk.ca/content/dam/Canada/AFFILIATE/ www-novonordisk-ca/OurProducts/PDF/victoza-productmonograph.pdf. 